\title{
INTRODUCTION: ECOLOGY AND CHINESE PHILOSOPHY
}

Appearances can be deceiving. The term "ecology" makes one think of the science of nonhuman communities of life. Connecting "ecology" with "philosophy," furthermore, evokes Western environmental ethics. Appearances are rooted in reality, even when they are deceptive, and these associations are no different. Ecology certainly studies the interactions of life in nature, and its concerns are the dynamic balances and energetic interplays of ecosystems and their environments. Environmental ethics, moreover, is an obvious point of contact between ecology and philosophy, and one of its pioneering approaches styles itself as deep ecology.

The problem is that these apparently self-evident associations are dated. Reality is different now because our ecological impact is in overshoot of planetary boundaries. The environmental difference between the past century and ours concerns types of degradation, the meaning of pollution, and the scope of extinctions. Before the new millennium, degradation consisted of local events and regional blights. The disasters in Chernobyl and Bhopal come to mind. A postmillennial example of this kind of degradation is the Deepwater Horizon oil spill. But in the new millennium, a new category of degradation has become central: climate change. Its processes, from greenhouse gases to global warming, had been understood since the 1940s; its drivers, rising concentrations of atmospheric carbon dioxide, had been measured since the 1950s; its arrival, in the guise of global warming, had been predicted since the 1970s; and its harbingers, record heatwaves, entered political discourse in the 1980s. In 1997, a first emission protocol, at Kyoto, was signed by representatives of most developed nations, with the notable exception of the United States. In the late 1990s, annual arctic sea ice minimum began to fluctuate, and in the early 2000s, it commenced its precipitous decline. In 2007, United Nations Secretary-General Ban Ki Moon pointed to climate change as a culprit in the humanitarian catastrophe in Darfur. With the polar ice

MARTIN SCHÖNFELD, Professor, Department of Philosophy, University of South Florida. Specialties: climate philosophy, environmental ethics, comparative philosophy, Kant. E-mail: mschonfe@usf.edu

Journal of Chinese Philosophy 43:3-4 (September-December 2016) 178-184 (C) 2018 Journal of Chinese Philosophy 
cap shrinking and the monsoon failing to reach the northeast African coast, climate change has become the new face of the ecological crisis.

Climate change changes our collective reality, because its effects are only local but also global, and it affects not only the biota of the environment but also its underlying cycles. As this new environmental impact degrades the global system, it threatens to unravel the integrity of our planetary habitat. Climate change also changes the meaning of pollution. Before, pollution was the spread of poisons, such as radioactive fallout at Chernobyl, deadly gas at Bhopal, and crude oil in the Gulf of Mexico. But with climate change, pollution is the spread of nontoxic compounds, such as carbon dioxide. If left undisturbed in coal, gas, and oil deposits, carbon compounds are safe; and if taken up in plant matter and wood fiber, carbon is beneficial. But its impact is greater than the pollutants of old, and its destructiveness arises from displacement. Pollution, now, is "matter out of place." The main ecological threats of displacing $\mathrm{CO}_{2}$ into the atmosphere are extinction and ecocide. This is the biggest difference between "then" and "now." In the last century, extinctions had been limited in scope and mostly threatened certain plants and animals, which is reflected in legislation such as the U.S. Endangered Species Act. In this century, the sixth mass extinction of Earth history is under way. In the second decade, its scope already compares to the extermination of the dinosaurs 62 million years ago. Its eventual size will depend on the level at which climate change can be reined in against U.S. opposition. If global warming stays within the two-degree limit of the Paris Accord, the sixth mass extinction will be less sweeping than the fifth that ended the Cretaceous. But if we crash through the two-degree guardrail, and global mean surface temperatures rise three or more degrees above the preindustrial baseline before this century is out, it could wipe out one half to three quarters of planetary biodiversity.

George Orwell famously wrote in Nineteen Eighty-Four, if you want a picture of the future, imagine a boot stamping on a human face-forever. Adapting this dictum to our reality, one could say, if you want a picture of the present (not the future), imagine a boot stamping on the face of nature, maybe not forever, but at least for the next one or two thousand years, given the longevity of the carbon pulse triggered in the 1850 s. This brings the big picture into view. The simplest way of differentiating "before" and "after," of distinguishing the past from the present, is that the human footprint on the planet squashed the stability of the last interglacial. The fertile harmony of the Holocene is over, and the storms, droughts, and floods of postHolocene harshness have begun. Civilization's impact on environmental services and system capacity is so momentous that it has ushered in a new geological period, the Anthropocene. 
What does this mean for ecology, for environmental ethics, and for Chinese philosophy? The human impact on the Earth system shatters all previous constraints. It collides with biogeochemical system parameters, the planetary boundaries, such as the assimilative capacity of the carbon cycle. It also marks the arrival at the environmental limit of economic growth. Crossing sustainable yield thresholds and moving into ecological overshoot, finally, dissolves the familiar distinction of culture and nature. As $\mathrm{CO}_{2}$ emissions transform nature throughout, we find ourselves with no pristine wilderness left. We have altered the air, the seas, and the land. The atmosphere is now a different mix of chemicals than it was before. Water in the oceans is now more acidic than it had been, and water on land is less evenly distributed than it used to be. Land is affected by sea level rise, extreme weather, and erosion, as well as by deglaciation, desertification, and economic and urban conversion. Everywhere, in the seas and on land, nature thus transformed is affected by vastly accelerated biodiversity loss.

As the wall between nature and culture comes tumbling down, ecology is not just the study of nonhuman communities anymore. It used to be concerned with nature, and now it straddles nature and culture. Human ecology, social ecology, and urban ecology are some of its new branches. Likewise, as the wall is coming down, environmental ethics is not the best interface of ecology and philosophy anymore, because the new reality is not reducible to interspecies conflicts, to a collision of human and nonhuman interests. The Anthropocene puts humans and nonhumans in the same boat. As we overload the global system, environmental integrity and biodiversity suffer first, and geopolitical security and economic stability do so next. Climate ethics, the new offshoot of environmental ethics, is not necessarily a better interface either, since our impact on climate does not amount to a purely moral problem. Climate change pushes civilization into crisis. It highlights our maladaptation as less a matter of personal choice and more a matter of collective structure. Ever more ethnic migrations, widening resource conflicts, and deepening food insecurity define the new reality. The profitability of fossil fuel extraction, refinement, and combustion has redrawn the battle-lines of the conflict. Humans and nonhumans find themselves on the same side, and free market capitalism is now on the other. This turns the old human-nature clash into an unprecedented collision of collective existential desires with neoliberal corporate profit, and this collision is manifest in economic, social, and political terms.

As this shifts the focus of reason from values to survival, from fairness to harmony, and from environmental protection to postcarbon sustainability, Chinese wisdom suggests a better bridge between ecology and philosophy. The issues of the Anthropocene, with the 
acceleration of climate change, and the need for decarbonization and transitioning to sustainability, demand solutions that go beyond the ethical to the existential and gain an evolutionary aspect. We have ruined the Holocene by building civilization on growth-based market economies despite dwelling in a finite habitat defined by planetary boundaries. We can prevail by readapting to system limits, and by steering the human society back into the flow-space of the biosphere.

The seven articles of this issue illustrate the ecological potential of Chinese philosophy for future-oriented thinking in the Anthropocene. "Henry Bugbee, Wilderness, and the Omnirelevance of the TenThousand Things," by James Hatley, is a study of a little-known American sage whose thought anticipated the paradigm shift imposed by the Anthropocene on environmental thought. Henry Bugbee (1915-1999) studied at Princeton and Berkeley, and wrote a spiritual diary, The Inward Morning (1958), which the religious scholar Huston Smith praised as "the most Daoist western book I know," a judgment Hatley defends and elaborates. Perhaps because The Inward Morning was so visionary, its publication sabotaged Bugbee's chances for tenure at Harvard, and so he left for Montana. Just as climate change confronts civilization with system limits, and as environmental thought in the Anthropocene is poised to take an existential turn, Bugbee proceeds from a Daoist stance, wuwei 無為 or letting things be, and wuzhi 無知 or a welcoming of empty knowing, to relate to nature harmoniously. Hatley argues that Bugbee's thought begins "not in irony and critique, not in a stance of distancing oneself from the natural world as it is given, but in faith, which is to say, in attentive affirmation of the ten-thousand things as they emerge in their own time and place". By shifting away from postmodern deconstruction and analytic dissection towards existential spirituality, Bugbee strikes a bridge from Daoist wisdom to ecological thought in the Anthropocene.

"An Exploration into Neo-Confucian Ecology," by Nicholas S. Brasovan, shifts the focus from Daoism to Confucianism, or from Laozi 老子 to Wang Fuzhi 王夫之 (1619-1692), a thinker in the transitional period from Ming to Qing dynasties. Wang Fuzhi's cosmology is grounded in the Book of Changes or Yijing 易經. Brasovan argues that this Neo-Confucian outlook lends itself to an ecological reconstruction for mastering the challenges of the twenty-first century. The difficulty with cognizing climate change-sadly illustrated by the scientific illiteracy of American conservatives-is that climate is a complex system whose properties differ from those of simple objects. U.S. Republicans famously appeal to cold weather to deny global warming, such as incumbent Senator Jim Inhofe (R-Oklahoma), Chair of the Senate Committee on the Environment, who produced a snowball on the Senate Floor in February 2015 as evidence that climate change is a 
hoax - to the right-wing mind, a cold thing disproves the warming trend of a complex system. Remarkable about the American disenlightenment is that this event unfolded in perfect seriousness; none of the gathered Senators burst out laughing, in contrast to how parliamentarians would react to such silliness anywhere else in the world. In his study of Wang Fuzhi, Brasovan explains complex systems in ecological discourse, describes natural cosmology in early modern Chinese thought, and makes a case for the ecological reconstruction of Neo-Confucianism based on reading tian 天 (usually translated as "day," "sky," or "heaven") as nature in Wang Fuzhi's work. Appropriately prescient for the Anthropocene, Wang Fuzhi comments on the Yijing that knowing nature is to know its patterns. Branovan translates a statement by Wang Fuzhi as, "When persons achieve position in equilibrium (with the cosmic forces of heavens and earth), then they can follow the model of the heavens and the earth and be without dread". This should be the motto of the Intergovernmental Panel on Climate Change.

The third contribution to the special issue on ecology is "When There Are No More Cats to Argue About," by Steven Heine. This examination reveals a profound ambiguity in chan 禪 views on animals, especially dogs and cats, which not only figure prominently in teaching parables and religious images but are also living fixtures at Buddhist temples, cats to control pests, and dogs to guard the grounds. On the one hand, chan images depict cats and dogs with people and deities, which evokes a holistic world, a non-anthropocentric outlook, and the universality of Buddha nature; on the other hand, such animals cannot be enlightened (e.g., to be taught to like vegetarian food), and so they do not understand Buddhist precepts. Moreover, some koans or gong-an 公案 regarding cats and dogs are rather callous. Heine concludes that chan discourse on animals is "decidedly mixed and inconclusive, and therefore committed to the noncommittal". This non-answer raises a question: what to make of chan in the Anthropocene? Is its irony a liability? But are its humility and frugality not rather assets? Either way, inner freedom should make civil evolution and transitioning to sustainability easier.

"Rethinking the Daoist Concept of Nature," by David Chai, pushes the exploration of the potential of Chinese wisdom for informing a sustainable civilization to another level. Chai worries about misappropriating tenets of Daoism in an environmental context. Nature should be understood as an extension of Dao's mystery. Patterns or wen 文 and orderings or $l i$ 理 can lead one astray; and Laozi and Zhuangzi 莊 子, despite their differences, share a reverence for the unknown. After an analysis of cosmogonic evolution in Daodejing 42, Chai arrives at the crucial question, of how humankind can establish a meaningful 
relationship with nature, given its cosmological ties to Dao, the one, and the many. German philosophy offers a pathway to Chinese wisdom, with Heidegger's notion of the fourfold (Geviert; the existential juncture between heavens and Earth, vis-à-vis the mortals and the gods; cf. also Daodejing 25). Chai contends that humanity is tasked "with expanding our knowledge of Nature by darkening our subjectivity (i.e., 'sit-and-forget,' zuowang 坐忘) via fasting of the mind (xinzhai 心齋)". In the Dao, the fourfold discloses itself as a mystery of conjoining, becoming, and flourishing. Chai concludes, "this is the genius of Daoism's insight into Nature-we are one of four not one plus three". Partaking in this genius is the essence of civil evolution towards ecological harmony in the Anthropocene.

"Daoist $c i$ (慈), Feminist Ethics of Care, and the Dilemma of Nature," by Ann A. Pang-White, shifts the Daoist lens from the ontological to the ethical, and from the spiritual to the practical. The concept $c i$ 慈, commonly translated as kind, merciful, and humane, has not received the attention it deserves. Unlike Confucian notions such as ren 仁, Daoist $c i$ remains a lacuna in comparative scholarship. Pang pursues a twofold argument: in the Daodejing, $c i$ is a fundamental notion, and it explains the feminist orientation of Daoism contra Confucianism. Secondly, in contemporary care ethics, $c i$ lends itself as an integrative idea to make care ethics impervious to conventional objections. Thus, $c i$ suggests yet another connection between east and west, between ancient Daoism and feminist critique, resonant with ecological meaning. Reminiscent of Paracelsus in German mysticism, Pang points out how feminist Daoism, as in the medical diagram Neijing Tu 內經圖, mirrors body and environment as a symmetry of human microcosm and ecological macrocosm. Such information may have been poetic and obscure in the Holocene, but it should now become an earthy and pragmatic meme to inform our cultural survival gear in the Anthropocene.

Stephen R. Palmquist and Keith Ka-Fu Chan contribute "A Confucian-Kantian Response to Environmental Eco-Centrism on Animal Equality." Their article offers a more global perspective. As Palmquist and Chan compare Confucianism to Western thought, it must be noted that Kantianism is a misfit in the Anglophone West, since these ideas rather belong to the European West. Continental Europe, Germany, the Nordic countries, and Russia alike claim him as one of their own; progressive Latin American thought is influenced by him; China has decreed him to be a world philosopher, and in Japan's temple of philosophy, his image is next to those of Socrates, Confucius, and the Buddha. Examining Confucianism and Kantianism with regard to animals, Palmquist and Chan argue that neither outlook quite deserves the charge of anthropocentrism. Confucianism does 
not, because humankind's value is tied to the Mandate of Heaven or tian ming 天命 by way of "the ethical-ontological substance of heaven and earth" that is sincerity or cheng 誠. Kantianism does not either, because the intrinsic value of humankind rests not only on "personality" (the capacity for the moral law) and on "humanity" (the capacity for rationality) but also on animality, on our embodied lives as sentient beings. Thus, either outlook supports universal care but not equal love. To the extent we are animals, we remain superior. In the Holocene, this was read as an arbitrary entitlement; in the Anthropocene, it becomes our fateful responsibility. Whether we like it or not, climate change is forging our destiny as global system managers and stewards of life on Earth.

The final contribution, "Greening Confucius: Appropriating the Analects for a Future-Oriented Reading," by Martin Schönfeld, is on the work that resists ecological reconstruction the most. Hatley, Chai, and Pang-White build a bridge to ecology on a Daoist platform. Heine problematizes such a bridge in the ambiguities of chan, but chan is still part of Buddhism, whose central value is compassion, and whose deepest insight is the lack of distinctions among sentient life. Brasovan, Palmquist, and Chan build an ecological bridge on a Confucian basis, by appealing to Wang Fuzhi, Mencius 《孟子》, and the Doctrine of the Mean or zhongyong 《中庸》. But what to make of the first text of Confucianism, Lunyu 《論語》 or the Analects? Schönfeld suggests a freely selective reading, to dismiss its chauvinist liabilities, analogous to the exegetical strategy of Christian theologians who embrace the Bible but ignore its stupid parts, such as Leviticus. Schönfeld argues that such an appropriation is suited for the Anthropocene because the Confucian model of development, purged from its patriarchic bias, offers a gender-neutral and cosmopolitan pathway of civil evolution.

In conclusion, I would like to thank my friend and colleague Eric S. Nelson for his careful editing of this issue, Linyu $\mathrm{Gu}$ for her patient support and helpful advice, and Chung-ying Cheng for his lasting philosophical inspiration.

\section{ENDNOTES}

Acknowledgment of Copyrights and Credentials: 